\title{
EDUCAÇÃO FINANCEIRA: UMA POSSIBILIDADE DE INTEGRAÇÃO COM A EDUCAÇÃO ESTATÍSTICA
}

\author{
FINANCIAL EDUCATION: A POSSIBILITY OF INTEGRATION WITH \\ STATISTICAL EDUCATION
}

\author{
Andréa Pavan Perin \\ Faculdade de Tecnologia de Itapetininga - FATEC \\ andreapavanperin@gmail.com \\ Celso Ribeiro Campos \\ Pontifícia Universidade Católica de São Paulo - PUC-SP \\ crcampos@,pucsp.br
}

\begin{abstract}
Resumo
Neste texto buscamos mostrar a integração da Educação Estatística com a Educação Financeira, mediante a realização de uma atividade de modelagem matemática envolvendo o tema inflação. A atividade foi realizada em uma turma de trinta e dois alunos do $3^{\circ}$ ano do Ensino Médio. Ao final do trabalho os alunos, em grupos, escreveram um texto argumentativo sobre o tema estudado. Esses textos constituíram a fonte de pesquisa e foram analisados por meio da técnica do Discurso do Sujeito Coletivo. Nossas análises mostram que essa integração foi possível tendo como suporte a busca por uma medida estatística para indicar a variação dos preços em um determinado período. As análises dos dados revelam também o desenvolvimento da competência crítica, a qual se deu por meio da construção de dois tipos de crítica, as quais denominamos de crítica epistemológica e sociopolítica. A crítica sociopolítica caracterizou-se pelas discussões sobre os impactos da inflação na vida das pessoas, enquanto a crítica epistemológica foi representada pelas ponderações sobre a escolha da melhor medida estatística para representar a taxa de inflação. Verificamos também que esse tipo de crítica possui relações com raciocínio estatístico.
\end{abstract}

Palavras-chave: Educação Estatística. Educação Financeira. Competência Crítica. Modelagem Matemática.

\begin{abstract}
This study aims to identify elements that show the possibility of integrating Statistics with Financial Education in Mathematics classes for high school, in the context of the pedagogical strategy named mathematical modelling, in which we worked on a didactic experience involving the theme inflation. For the analysis of the collected material (final activity report) we used the qualitative approach, through the analysis of the Collective Subject Discourse. Our analyzes show that this integration was possible based on the search for a statistical measure, average or median, to indicate the price variation in a given period. Data analysis also reveals the development of critical competence, which took place through the construction of two types of criticism, which we call epistemological and
\end{abstract}


socio-political criticism. Socio-political criticism is characterized by an analysis of social structures (problematic, from their point of view) for the studied phenomenon, which was the inflation rate. The epistemological criticism, on the other hand, refers to the reflection on the choice of the best statistical measure to represent this rate, considering the procedures, methodologies and results achieved. We have also found that this type of criticism has relations with statistical reasoning.

Keywords: Statistical Education. Financial Education. Critical Competence. Mathematical Modelling.

\section{INTRODUÇÃO}

Desde 2018 o Brasil passou a adotar a nova Base Nacional Comum Curricular (BNCC), a qual orienta as escolas da educação básica acerca dos objetivos, conteúdos e habilidades relacionados a cada área de ensino. Esse documento estabelece que o ensino de Matemática deve priorizar metodologias investigativas:

Os processos matemáticos de resolução de problemas, de investigação, de desenvolvimento de projetos e da modelagem podem ser citados como formas privilegiadas da atividade matemática, motivo pelo qual são, ao mesmo tempo, objeto e estratégia para a aprendizagem [...] Esses processos de aprendizagem são potencialmente ricos para o desenvolvimento de competências fundamentais para o letramento matemático (raciocínio, representação, comunicação e argumentação) e para o desenvolvimento do pensamento computacional (BRASIL, 2018, p. 266, ênfase do autor).

A Matemática e a realidade são apresentadas no documento no contexto do Ensino Médio, citando como competência específica:

Utilizar estratégias, conceitos e procedimentos matemáticos para interpretar situações em diversos contextos, sejam atividades cotidianas, sejam fatos das Ciências da Natureza e Humanas, das questões socioeconômicas ou tecnológicas, divulgados por diferentes meios, de modo a contribuir para uma formação geral (BRASIL, 2018, p. 532).

O desenvolvimento dessa competência específica pode ser trabalhado por meio de projetos de modelagem matemática, na medida em que estes buscam trazer problemas reais de diversas naturezas (inclusive de fora da Matemática), para serem avaliados e resolvidos por meio da Matemática. Nessa linha, essa competência pressupõe "habilidades que podem favorecer a interpretação e compreensão da realidade pelos estudantes, utilizando conceitos de diferentes campos da Matemática para fazer julgamentos bem fundamentados" (BRASIL, 2018).

Os estudantes deverão, por exemplo, ser capazes de analisar criticamente o que é produzido e divulgado nos meios de comunicação (livros, jornais, revistas, internet, televisão, rádio etc.), muitas vezes de forma imprópria e que induz a erro: generalizações equivocadas de resultados de pesquisa, uso inadequado da amostragem, forma de representação dos dados - escalas inapropriadas, legendas 
não explicitadas corretamente, omissão de informações importantes (fontes e datas), entre outros (BRASIL, 2018, p. 532).

Nesse trecho da BNCC vemos como o documento valoriza o conhecimento estatístico, que por sua vez pressupõe o letramento estatístico e a competência crítica.

Ainda na BNCC, destacamos a competência específica:

Utilizar estratégias, conceitos, definições e procedimentos matemáticos para interpretar, construir modelos e resolver problemas em diversos contextos, analisando a plausibilidade dos resultados e a adequação das soluções propostas, de modo a construir argumentação consistente (BRASIL, 2018, p. 535).

Novamente a resolução de problemas e a modelagem matemática entram em pauta nessa competência, cujas habilidades relacionadas referem-se à "interpretação, construção de modelos, resolução e formulação de problemas matemáticos envolvendo noções, conceitos e procedimentos quantitativos, geométricos, estatísticos, probabilísticos, entre outros" (BRASIL, 2018, p. 535). Como se vê, os conhecimentos estatísticos estão diretamente imbricados nessa competência.

Para a formulação, modelação e resolução de problemas, o documento ressalta que é importante contemplar contextos diversos, pois "os estudantes devem desenvolver e mobilizar habilidades que servirão para resolver problemas ao longo de sua vida - por isso, as situações propostas devem ter significado real para eles” (BRASIL, 2018, p. 535).

Por fim, entre as habilidades descritas para a área de Matemática no ensino médio na $\mathrm{BNCC}$, nos toca examinar três delas:

(EM13MAT104) Interpretar taxas e índices de natureza socioeconômica (índice de desenvolvimento humano, taxas de inflação, entre outros), investigando os processos de cálculo desses números, para analisar criticamente a realidade e produzir argumentos.

(EM13MAT203) Aplicar conceitos matemáticos no planejamento, na execução e na análise de ações envolvendo a utilização de aplicativos e a criação de planilhas (para o controle de orçamento familiar, simuladores de cálculos de juros simples e compostos, entre outros), para tomar decisões.

(EM13MAT101) Interpretar criticamente situações econômicas, sociais e fatos relativos às Ciências da Natureza que envolvam a variação de grandezas, pela análise dos gráficos das funções representadas e das taxas de variação, com ou sem apoio de tecnologias digitais. (BRASIL, 2018, p. 543).

Nessas competências, observamos uma conexão com a área econômico-financeira, inclusive com a citação explícita da taxa de inflação. Entendemos que isso abre uma boa possibilidade de conectar a Matemática, a Estatística e a Educação Financeira.

Tendo em vista os objetos de conhecimento, as competências e as habilidades citadas, 
além da forma preconizada para trabalhar com elas com vistas ao desenvolvimento dessas habilidades, este estudo tem como objetivo mostrar a integração da Educação Estatística com a Educação Financeira mediante a realização de uma atividade de modelagem matemática envolvendo o tema inflação. Nossa opção por esse tema reside no fato de que ele envolve uma grandeza estatística (número índice) de grande importância para o mundo das finanças, como também traz implicações políticas e têm impacto na vida de todos, pois representa um fenômeno (aumento generalizado de preços de produtos e serviços) que afeta e, de certa maneira, assombra os consumidores em geral, com consequências mais severas para os mais vulneráveis social e economicamente.

$\mathrm{Na}$ atividade pedagógica aqui descrita a Educação Financeira se apresenta como um tema transversal na aula de Matemática na Educação Básica. O fio condutor foi composto por dois conceitos importantes da Estatística, a média e mediana, os quais foram abordados levando-se em consideração os pressupostos da Educação Estatística Crítica. Sena (2017), ao estudar as habilidades do letramento financeiro concluiu que elas convergem com o modelo de letramento estatístico de Gal (2002) e com isso reforça a possiblidade de que a Educação Financeira seja trabalhada por meio da Educação Estatística.

$\mathrm{Na}$ sequência apresentamos o referencial teórico sobre Educação Estatística e Educação Financeira que sustentaram esta pesquisa.

\section{EDUCAÇÃO ESTATÍSTICA}

A Educação Estatística como área de estudos e pesquisas formou-se com base nas preocupações advindas da formação de profissionais, professores e estudantes que, de alguma forma, estão ligados à Estatística. Por essa razão, trata-se de uma aproximação entre duas áreas de conhecimento, a Educação e a Estatística. A Educação Estatística tem como foco de trabalho os seguintes temas: conteúdo a ser ensinado (quais, como e por quê?); organização dos programas; formação/preparo de estudantes, profissionais da área e professores que ensinarão Estatística. No contexto brasileiro, as pesquisas têm-se de desenvolvido com base no estudo de três competências, a literacia, o raciocínio e o pensamento estatísticos (CAMPOS, 2007; PERIN, 2019; PERIN e CAMPOS, 2020). Dados os objetivos deste artigo, discutiremos apenas a literacia e o raciocínio estatísticos.

A literacia está relacionada à capacidade de ler e interpretar dados contidos em tabelas 
e gráficos, verificar se as conclusões presentes em uma informação podem ser obtidas com base nos dados disponíveis e compreender os conceitos envolvidos entre a inferência e a tomada de decisão. Essa competência envolve a análise conceitual de informações e a postura crítica frente às estatísticas presentes nos meios de comunicação.

Por literacia estatística entende-se o estudo de argumentos que usam a Estatística como referência, ou seja, a habilidade de argumentar usando corretamente a terminologia Estatística. Ela inclui a capacidade de organizar dados, construir e apresentar tabelas, trabalhar com diferentes representações de dados, compreender conceitos, vocabulários, símbolos e as probabilidades como medidas da incerteza (CAMPOS, WODEWOTZKI e JACOBINI, 2011).

Gal (2002) propõe o que chama de modelo de literacia estatística, o qual pressupõe que ela requer a mobilização conjunta de componentes cognitivos e afetivos. O componente cognitivo é composto por cinco elementos de conhecimentos inter-relacionados. O segundo componente, afetivo, é composto por dois elementos, pois os elementos de disposição dependem da competência para propor perguntas e ativar uma postura crítica, que, por sua vez, envolve crenças e atitudes. Os componentes desse modelo com seus respectivos elementos estão organizados no Quadro 1.

Quadro 1 - Modelo de Literacia Estatística

\begin{tabular}{|c|c|}
\hline \multicolumn{2}{|c|}{ Letramento Estatístico } \\
\hline Elementos do conhecimento & Elementos de disposição \\
\hline Habilidade de letramento & \\
Conhecimento estatístico & Crenças e atitudes \\
Conhecimento matemático & Posicionamento crítico \\
Conhecimento contextual & \\
Questionamento crítico & \\
\hline
\end{tabular}

Fonte: Gal (op.cit., p. 4)

Perin (2019) mostra que essa competência está associada ao uso que um indivíduo faz do conhecimento estatístico para compreender o que não está necessariamente explícito em uma informação estatística. Não se trata apenas de saber-fazer, mas de compreender o quê, como e por que fazer de determinada forma em um contexto específico, e, ao fazê-lo, ter ciência das implicações do que se faz. 
O raciocínio está mais ligado à compreensão conceitual e à conexão de importantes ideias, como variação, distribuição, centro, dispersão, associação, amostragem e combinação de ideias sobre dados e incerteza, o que conduz a realização de inferência.

Para que os estudantes possam desenvolver essa competência, as tarefas em sala de aula devem ser preparadas com o objetivo de levar os alunos ao desenvolvimento de ideias estatísticas centrais. É necessário que elas conduzam ao aprofundamento da compreensão conceitual em Estatística, ao invés da aprendizagem de procedimentos e representações específicas. Algumas dessas ideias centrais, segundo Biehler et al. (2018) são:

- Dados: O objetivo é perceber a necessidade dos dados para tirar conclusões e fazer avaliações. Aspectos ligados à obtenção de dados que sejam válidos devem ser também contemplados;

- Distribuição: A ideia é levar os alunos a terem uma visão global dos dados de modo a desenvolverem a noção de distribuição;

- Variabilidade e centro: Deve-se incentivar a conjugação da análise de medidas de tendência central com a dispersão dos dados, medida, por exemplo, pela amplitude da amostra e pela amplitude interquartis;

Perin e Wodewotzki (2019) afirmam que o raciocínio estatístico concerne ao trabalho com as ferramentas estatísticas, buscando compreender os seus significados mais profundos. Para as autoras, raciocinar estatisticamente significa estar atento ao sentido dessas ferramentas, à mensagem que elas trazem subjacentes, principalmente no contexto em que são utilizadas.

Campos (2016) salientou que desenvolver essas competências estatísticas conduz ao desenvolvimento de uma outra competência, a crítica. Para o autor, quando os alunos trazem para a sala de aula problemas do seu cotidiano, eles são desafiados a pensar sobre o que os dados indicam a respeito a realidade e isso os torna mais críticos. Para o autor, problemas baseados em dados reais é a chave para desenvolver a criatividade e a criticidade.

Perin e Wodewotzki (2019) explicam que a competência crítica decorre da construção de dois tipos de crítica, denominadas por elas de sociopolítica e epistemológica. A crítica sociopolítica é aquela que aborda questões ligadas ao entendimento de aspectos do mundo em que vivem os indivíduos, bem como de suas atuações nesse mundo. A crítica epistemológica refere-se às percepções em relação ao conhecimento estatístico e está 
fortemente relacionada com as competências estatísticas.

\section{EDUCAÇÃO FINANCEIRA}

Conceitos, conhecimentos, competências e habilidades matemáticas e estatísticas são necessários para as atividades econômicas e financeiras mais triviais realizadas pelas pessoas comuns em seu cotidiano. Hofmann e Moro (2012) destacam que

Compreender, em alguma medida, os fundamentos econômicos, sociais, legais e mesmo linguísticos subjacentes às práticas econômicas cotidianas é condição para a interação e para a socialização econômica da população. A familiaridade com noções como propriedade, valor, preço e juros, por exemplo, e a capacidade de leitura e interpretação de documentos financeiros são exemplos de elementos que fazem parte da educação financeira da população, seja de forma institucionalizada, em ambientes de ensino como a escola, seja informalmente, mediante processos sociais e familiares de introdução à lógica econômico-financeira (HOFMANN e MORO, 2012, p. 47)

A Educação Financeira (EF) foi introduzida oficialmente no Brasil por meio da criação da Estratégia Nacional de Educação Financeira (ENEF), em 2010, seguindo recomendações da Organização para Cooperação e Desenvolvimento Econômico (OCDE). A ENEF foi criada pelo Banco Central do Brasil, em parceria com organizações reguladoras da área financeira, e resultou na criação de farto material de divulgação que foi distribuído às escolas públicas de nível fundamental e médio. Recentemente, com a promulgação da BNCC (Brasil, 2018), a educação financeira tornou-se um componente obrigatório para a escola básica, sendo tratada como um tema transversal no ensino médio.

Em Campos e Perin (2020), observamos que a EF promovida pela OCDE tem um enfoque predominante que chamamos de vertente instrumental, o qual trata o cidadão como consumidor de produtos financeiros. Tal vertente pode ser observada na definição de educação financeira da OCDE:

Processo mediante o qual os indivíduos e as sociedades melhoram a sua compreensão em relação aos conceitos e produtos financeiros, de maneira que, com informação, formação e orientação, possam desenvolver os valores e as competências necessários para se tornarem mais conscientes das oportunidades e riscos neles envolvidos e, então, poderem fazer escolhas bem informadas, saber onde procurar ajuda e adotar outras ações que melhorem o seu bem-estar (OECD, 2005 , p. 26, tradução nossa, destaque nosso).

Em nosso entendimento, a EF deve ser exercida em um contexto de educação para o exercício da cidadania, o qual pressupõe que os indivíduos devem ser estimulados a perceberem e exercerem seus direitos e deveres tanto em um sentido coletivo como 
individual, participando ativamente da vida em sociedade, respeitando ao outro, mas também exigindo respeito para si. "[...] esse conceito de educação transcende as limitações das disciplinas escolares e se impõe como um objetivo maior e mais abrangente, que se sobrepõe inclusive ao tempo, pois pode e deve ser trabalhado desde os níveis mais básicos da vida estudantil (CAMPOS e PERIN, 2020, p. 241).

Ao mesmo tempo, esse conceito se aproxima fortemente da ideia de Educação Crítica, na medida em que esta defende um ambiente pedagógico democrático, que busca o desenvolvimento, nos alunos, de um espírito crítico, responsabilidade ética e conscientização política.

Falando em termos de finanças pessoais, entendemos que a EF consiste em

um esforço pedagógico transdisciplinar que deve buscar a conscientização das pessoas para a importância de uma gestão eficiente de seu orçamento individual e familiar, no sentido de alertar sobre as consequências do consumismo, das propagandas enganosas de produtos e serviços, das armadilhas do sistema financeiro imposto pelos bancos que praticam taxas de juros altíssimas nos empréstimos, das graves consequências do superendividamento e da inadimplência que se mantêm em níveis altos ao longo do tempo, prejudicando principalmente as classes sociais mais vulneráveis, etc. (CAMPOS e PERIN, 2020, p. 241).

Por meio desse raciocínio, vemos que a EF transcende a Matemática Financeira, passando a ter um caráter multidisciplinar, necessário para se alertar sobre as consequências de uma má gestão do dinheiro, e promovendo o letramento financeiro em um contexto que diz respeito à vertente crítica da Educação Financeira. Essa vertente, por sua vez, assume os pressupostos da educação crítica e defende uma postura de valorização da conscientização social e política presente nos conhecimentos necessários ao bom desenvolvimento da EF.

Nesse cenário, a BNCC também destaca a importância da EF em sua vertente crítica:

Há hoje mais espaço para o empreendedorismo individual, em todas as classes sociais, e cresce a importância da educação financeira e da compreensão do sistema monetário contemporâneo nacional e mundial, imprescindíveis para uma inserção crítica e consciente no mundo atual (BRASIL, 2018, p. 568).

Ainda na BNCC, a EF é citada como um aspecto que deve ser considerado dentro da unidade temática de Matemática, mas com caráter interdisciplinar:

Outro aspecto a ser considerado nessa unidade temática é o estudo de conceitos básicos de economia e finanças, visando à educação financeira dos alunos. Assim, podem ser discutidos assuntos como taxas de juros, inflação, aplicações financeiras (rentabilidade e liquidez de um investimento) e impostos. Essa unidade temática favorece um estudo interdisciplinar envolvendo as dimensões culturais, sociais, políticas e psicológicas, além da econômica, sobre as questões do consumo, trabalho e dinheiro (BRASIL, 2018, p. 269). 
É diante desse cenário que vamos apresentar neste artigo uma experiência pedagógica construída para trabalhar conceitos de EF no ensino médio, considerando seu caráter interdisciplinar e sua vertente crítica.

\section{ENCAMINHAMENTOS METODOLÓGICOS}

\section{A realização da atividade}

A experiência pedagógica que vamos relatar foi desenvolvida numa turma de trinta e dois alunos do $3^{\circ}$ ano do ensino médio (EM) de uma escola particular do interior de São Paulo. Os alunos foram divididos em oito grupos de quatro alunos e os temas pesquisados pelos grupos foram: preços de alimentos, remédios em farmácia, vestuário, transporte, hortifruti, serviços, eletroeletrônicos e bebidas. Todos os alunos participaram da atividade.

Em sua maioria, os alunos dessa turma recebem alguma remuneração, seja ela vinda do trabalho relacionado ao programa Jovem Aprendiz, bolsa de iniciação científica ou por frequentarem cursos técnicos profissionais. Essas atividades os estudantes realizam no período matutino e cursam o EM no período vespertino. Desde o início do ano letivo de 2020, a turma demonstrou interesse em assuntos relacionados à Educação Financeira. Muitos relatavam buscar informações nas redes sociais como canais no Youtube, perfis do Instagram e Telegram, mas queriam alguém mais próximo deles falando sobre o assunto. Tal curiosidade também foi despertada pelo fato de a professora, nas primeiras semanas de aula, comentar que havia um planejamento para trabalhar aspectos ligados à Educação Financeira.

Dado a necessidade do isolamento social, necessário por conta da pandemia da Covid-19, e alterações no calendário escolar, as atividades sobre Educação Financeira tiveram seu início do mês de junho. Não obstante, neste artigo restringimo-nos a relatar e analisar apenas a atividade desenvolvida entre os meses de agosto e setembro de 2020 . O cálculo do IPCA foi o tema sugerido pelos estudantes. As aulas foram realizadas à distância e de forma síncrona por meio do aplicativo Teams ${ }^{l}$. Para esta atividade foram destinados quatro encontros síncronos e três assíncronos. A estratégia pedagógica utilizada foi a modelagem matemática, mais especificamente o caso 3 de Barbosa (2001), o qual define que

\footnotetext{
${ }^{1}$ Teams é um aplicativo de comunicação empresarial que integra membros e informações de determinada instituição. A ferramenta reúne conversas, arquivos, reuniões e apps da equipe em um único espaço colaborativo.
} 
são os alunos quem escolhem o problema, coletam e analisam os dados. Para organizar as atividades desenvolvidas e descrevê-las, utilizamos como referencial as etapas da modelagem matemática definidas por Burack (2019).

- $1^{a}$ etapa - escolha do tema: Aconteceu em outras atividades do projeto sobre Educação Financeira, pois os alunos disseram ter interesse em compreender melhor o IPCA.

- $2^{a}$ etapa - pesquisa exploratória: Inicialmente os alunos fizeram uma pesquisa dos grupos de itens que compõem a cesta que determina o índice de inflação para um determinado período. Pesquisaram também como esse índice é calculado. Essa pesquisa retornou os seguintes agrupamentos: alimentação, vestuário, serviços, transportes, produtos em farmácia e outros. Feito isso, os alunos dividiram-se em equipes e escolheram o grupo da cesta que queriam pesquisar. Eles foram orientados a colocar no mínimo 10 e no máximo 15 itens em cada grupo. A coleta dos preços dos produtos foi realizada da seguinte forma: os estudantes pesquisaram o preço do produto no primeiro dia útil do mês de agosto e, novamente, no primeiro dia útil do mês de setembro. Anotaram todas as especificidades do produto pesquisado no mês de agosto, pois em setembro, deveriam buscar o preço do mesmo produto no mesmo estabelecimento, conforme exemplo mostrado na figura 1 . Tomou-se o cuidado de que os alunos não precisassem ir até o estabelecimento para realizar a pesquisa de preços, a qual foi feita por meio de sites, aplicativos de compra e de conversa. 
Figura 1 - Organização de informações sobre os itens pesquisados do grupo bebidas no supermercado.

\begin{tabular}{|c|c|c|c|}
\hline Grupo 8 - Bebidas em supermercado & Coluna1 & Coluna2 & Coluna3 \\
\hline item & $\begin{array}{c}\text { Descrição do intem } \\
\text { (marca, quantidade, ...) }\end{array}$ & $\begin{array}{c}\text { Preço } \\
\text { Agosto }\end{array}$ & $\begin{array}{c}\text { Preço - } \\
\text { Setembro }\end{array}$ \\
\hline leite integral & Piracanjuba-1L & $\mathrm{R} \$ 3,99$ & $\mathrm{R} \$ 4.19$ \\
\hline leite desnatado & Piracanjuba-1L & $\mathrm{R} \$ 3,69$ & $\mathrm{R} \$ 4.19$ \\
\hline água & Minalba-5L & $\mathrm{R} \$ 2,49$ & $\mathrm{R} \$ 7.68$ \\
\hline cerveja & Heineken-330ml & $\mathrm{R} \$ 3.49$ & $\mathrm{R} \$ 4.49$ \\
\hline chá & Leão Camomila-10un & $\mathrm{R} \$ 3,69$ & $\mathrm{R} \$ 3.59$ \\
\hline suco & Dafruta-1L & $\mathrm{R} \$ 3,39$ & $\mathrm{R} \$ 3.89$ \\
\hline refrigerante & Kuat-3L & $\mathrm{R} \$ 4,99$ & $\mathrm{R} \$ 5.79$ \\
\hline café solúvel & Café Três Coraçốes-500g & $\mathrm{R} \$ 7,95$ & $\mathrm{R} \$ 9.78$ \\
\hline iogurte & Batavo-540g & $\mathrm{R} \$ 3,99$ & $\mathrm{R} \$ 3.99$ \\
\hline bebida alcoólica & Whisky Jack Daniel's-1L & $\mathrm{R} \$ 119,90$ & $\mathrm{R} \$ 159.90$ \\
\hline toddynho & Toddynho-200ml & $\mathrm{R} \$ 2,39$ & $\mathrm{R} \$ 1.69$ \\
\hline água de coco & Puro CoCo-1L & $\mathrm{R} \$ 5,99$ & $\mathrm{R} \$ 5.99$ \\
\hline
\end{tabular}

Fonte: Atividade dos alunos

- $3^{a}$ etapa - levantamento dos problemas; $4^{a}$ etapa - resolução do problema e o desenvolvimento do conteúdo matemático no contexto do tema: Após a coleta de dados, os grupos compartilharam as informações no Excel online. Com isso, calcularam a média e mediana da variação percentual dos preços. Nessa fase os alunos tiveram que responder a seguinte questão: Por que a variação dos preços de sua cesta de produtos e serviços pode ser maior ou menor do que a medida pelos índices oficiais? Qual a melhor medida estatística a ser utilizada para representar a variação dos preços no período analisado?

- $5^{a}$ etapa - análise crítica da informação: Nessa etapa buscamos discutir os impactos do IPCA na renda do trabalhador. Para a mobilização foi sugerido a leitura de um texto $^{2}$, mediada pelas seguintes questões: Quais as consequências de um IPCA positivo para a economia da sua família? Você entende que determinada classe social pode ser mais afetada com o IPCA em alta? Por quê?

Dados os objetivos deste artigo, nossas análises residem, mais intensamente, sobre as discussões estabelecidas nas três últimas etapas da atividade de modelagem matemática.

\footnotetext{
${ }^{2}$ Disponível em: $<$ https://portalibre.fgv.br/noticias/igp-m-sobe-223-emjulho\#: :text $=\mathrm{O} \% 20 \% \mathrm{C} 3 \% 8$ Dndice $\% 20 \mathrm{Geral} \% 20 \mathrm{de} \% 20 \mathrm{Pre} \% \mathrm{C} 3 \% \mathrm{~A} 7 \mathrm{os}, \% 2 \mathrm{C} 39 \% 25 \% 20 \mathrm{em} \% 2012 \% 20 \mathrm{mes}$ es>
} 
Perin, A. P.; Campos, C. R.

\section{A organização dos dados}

Para fazer a análise referente às discussões estabelecidas entre os alunos e com a professora, recorremos à abordagem qualitativa, por meio da análise do Discurso do Sujeito Coletivo (DSC), conforme proposto Lefevre e Lefevre (2014).

Essa técnica permite, metodologicamente, resgatar e apresentar as Representações Sociais (RSs) obtidas de pesquisas empíricas. O conceito de RSs com que se trabalha nessa metodologia de análise é o mesmo produzido por Durkhein (2003) para quem toda maneira de fazer, agir e pensar dos indivíduos se dá no âmbito geral de uma sociedade e, ao mesmo tempo, em uma existência própria.

Submetidas ao processo de produção usado no DSC, as $\mathrm{RSs}$, sob a forma de depoimentos coletivos, veiculam histórias a respeito de um dado tema ou problema pesquisado. O diferencial dessa metodologia é que a cada categoria estão associados os conteúdos das opiniões de sentido semelhantes presentes em depoimentos distintos, de modo a formar com tais conteúdos um depoimento síntese (LEFEVRE e LEFEVRE, 2014).

$\mathrm{Na}$ presente pesquisa, o DSC foi utilizado com o emprego dos seguintes procedimentos:

- Etapa 1 - exploração: Leitura da produção escrita dos alunos sobre as discussões estabelecidas na $5^{\text {a }}$ etapa da atividade de modelagem matemática.

- Etapa 2 - expressões-chave: foram construídas com base nos fragmentos das transcrições literais dos depoimentos e visam apresentar a essência do conteúdo do discurso realizado pelos alunos.

- Etapa 3 - ideias centrais: Foram extraídas das expressões-chave, e foram o ponto de partida do DSC. Algumas mudanças foram realizadas nos fragmentos utilizados, no sentido de dar, às narrativas, uma sequência clara, mas sem o comprometimento do discurso do grupo.

- Etapa 4 - Discurso do Sujeito Coletivo: Advém da produção escrita, o qual busca retratar a literacia, o raciocínio estatístico e a competência crítica (sociopolítica e epistemológica).

\section{RESULTADOS E DISCUSSÕES}

Nos quadros 2 e 3 apresentamos, por meio do DSC, os argumentos dos alunos 
referentes à forma como a inflação é determinada, bem como as implicações dela na sociedade. Essas argumentações compõem o trabalho final/síntese dos grupos sobre a atividade desenvolvida. Para que essa síntese fosse produzida, foi estabelecida uma discussão numa aula síncrona com base nas seguintes questões norteadoras: Qual a inflação média e mediana do período? O que elas indicam/representam? Se seu grupo tivesse que escolher uma medida para representar a inflação do período, qual delas seria utilizada? Por quê? Alguma classe social pode ser a mais afetada pela inflação? Por quê? Ao se determinar o índice de inflação para um período ele é igual para todas as famílias brasileiras. O grupo concorda com essa afirmação? Argumente.

Quadro 2 - Discurso do Sujeito Coletivo sobre formas de representar a inflação.

A inflação média encontrada foi de 6,98\%. Isso quer dizer o "valor geral/genérico" que relaciona todo o conjunto de porcentagens encontradas do aumento dos preços dos produtos de agosto para setembro. $\mathrm{O}$ que significa que teve uma alta nos preços das mercadorias. Esse valor é calculado a partir da soma de todos os valores percentuais de inflação, dividido pela quantidade de itens. Tiveram produtos que zeraram a inflação, ou seja, não apresentaram alta nos preços (...) e também que tiveram redução do preço. A inflação mediana foi 0,00 . Metade dos preços teve deflação e a outra inflação. Sim, uma ${ }^{3}$ deu quase 7 e a outra 0 . A melhor medida, para o nosso grupo, é a Mediana pois consegue ter uma visão melhor do que teve inflação ou não, e também a média sofre com valores extremos e assusta a gente. Se a mediana da inflação der maior, quer dizer que tudo aumentou. Significa que metade dos preços estão abaixo da inflação e o resto está acima. As duas estão corretas, mas ao utilizar a mediana há uma maior precisão na estatística, em nossa opinião. Meu grupo acredita que a média é melhor, pois se as coisas sobem ou descem de preço já dá para ver, enquanto a mediana pode ficar sempre dando 0 e os preços de alguns produtos estão subindo e descendo. Se a média sofre com esses produtos que sobem muito, a mediana tem esse problema que nós apontamos. Eu acho que se for para pôr num jornal a média é melhor, pois haverá um número que pode ser discutido, já muitas vezes ela pode dar alta ou baixa apenas por conta de um grupo pequeno de itens, enquanto a mediana pode ser sempre zero e aí já não dá para discutir muita coisa.

Fonte: Material de pesquisa.

Analisando o discurso apresentado no quadro 2 vê-se que os alunos desenvolveram aspectos importantes da literacia e do raciocínio estatístico, em especial, sobre média e mediana, além da competência crítica.

Sobre as medidas de tendência central, além da capacidade de determiná-las, as falas dos alunos revelam a compreensão conceitual dessas medidas. Seus argumentos indicam que eles compreenderam que a média aritmética de um conjunto de dados é particularmente indicada para dados que possuem os valores simétricos em relação a um valor médio. Assim,

\footnotetext{
${ }^{3} \mathrm{O}$ grupo estava se referindo às medidas estatísticas utilizadas para determinar a inflação, as quais são a média e mediana
} 
demostraram o entendimento de que a média não representa bem um conjunto de dados que apresente valores extremos, ou seja, compreenderam que ela é grandemente influenciada por esses valores. Já no que diz respeito à mediana, os alunos perceberam que ela não é influenciada por valores extremos de uma série ou conjunto de dados. Além disso, enfatizaram que essa medida pode ser utilizada especialmente para distribuições assimétricas ou que apresentam outliers. Tais compreensões são possíveis de serem captadas quando afirmam: "A melhor medida, para o nosso grupo, é a Mediana pois consegue ter uma visão melhor do que teve inflação ou não, e também a média sofre com valores extremos e assusta a gente. Se a mediana da inflação der maior, quer dizer que tudo aumentou”. "Meu grupo acredita que a média é melhor, pois se as coisas sobem ou descem de preço já dá para ver, enquanto a mediana pode ficar sempre dando 0 e os preços de alguns produtos estão subindo e descendo. Se a média sofre com esses produtos que sobem muito, a mediana tem esse problema que nós apontamos".

Afirmamos que tais argumentos relacionam-se com o raciocínio estatístico, pois, para Bieher et al. (2018), o raciocínio sobre medidas de centro corresponde ao discernimento da melhor medida a ser utilizada em diferentes condições e porque algumas delas não podem representar aquele conjunto de dados. Com base na fala dos alunos, vê-se que eles não apenas calcularam essas medidas, média e mediana, mas sobretudo refletiram sobre o seu significado no contexto em que estavam sendo utilizadas. Os recortes apresentados vão ao encontro do afirmado por Perin e Wodewotzki (2019) de que o raciocínio estatístico se vincula ao trabalho com as ferramentas estatísticas, em especial, a mensagem subjacente a elas, principalmente a validação na circunstância em que estão sendo empregadas.

Essas falas apresentam também conexões com a literacia estatística, visto que essa competência envolve a análise conceitual de informações e uma postura crítica frente às demandas estatísticas. Asseguramos que os alunos demonstraram uma postura crítica, pois fizeram uma avaliação a respeito da medida mais adequada, o que pôde ser identificado nos trechos referentes a escolha da melhor medida. Estabelecendo um paralelo com o quadro de Gal (2002) vemos que diferentes tipos de conhecimentos foram mobilizados pelos alunos. O conhecimento contextual foi utilizado ao relacionarem a escolha da melhor medida estatística com a especificidade da situação analisada, "Meu grupo acredita que a média é melhor, pois se as coisas sobem ou descem de preço já dá para ver”. Observamos também a presença do 
conhecimento matemático, pois os alunos demonstram compreender como as variáveis podem influenciar o valor da média. Além disso, destacamos as crenças e atitudes, pois suas escolhas estão relacionadas com aquilo que acreditam ser importante: "se as coisas sobem ou descem de preço já dá para ver" ou "Mediana pois consegue ter uma visão melhor do que teve inflação ou não".

Tal postura revela o desenvolvimento da competência crítica, conforme defendido por Campos (2016), pois os alunos não apenas determinaram as medidas de posição central, mas argumentaram sobre suas ideias, criticando um ao outro suas interpretações e promoveram o julgamento e avaliação das conclusões obtidas mediante o trabalho realizado.

Denominamos críticas dessa natureza como epistemológicas, pois referem-se à validação do modelo estatístico, com um olhar atento para as suas potencialidades e fragilidades. Trata-se de uma análise crítica ao método, ao papel que as variáveis desempenham na obtenção do modelo, ou seja, pertencem aos argumentos relacionados ao conhecimento estatístico. Tem relações também sobre como as ideias estatísticas chegam aos consumidores dessas informações, o que se nota no seguinte trecho do DSC "meu grupo acredita que média é a melhor medida, pois se as coisas sobem ou descem de preço já dá para ver, enquanto a mediana pode ficar dando zero e o preço de alguns produtos estão subindo e descendo".

Adicionalmente, afirmamos que esse olhar/discussão em torno das características da média e da mediana colaborou com a Educação Financeira dos estudantes, pois eles se apropriaram, em alguma medida, de conceitos financeiros subjacentes às práticas econômicas, conforme defendido por Hofmann e Moro (2012). No caso dessa experiência pedagógica, o conceito trabalhado foi a taxa de inflação. Asseguramos também que essa atividade atendeu aos objetivos propostos pela BNCC para a Educação Financeira, uma vez que esse documento propõe que, por meio da Matemática, os alunos aprendam conceitos básicos de economia e finanças.

Sobre a atividade realizada, as análises não se restringiram aos resultados dos modelos estatísticos. Os alunos também foram questionados sobre as implicações desse fenômeno na vida das pessoas e para a sociedade. Esse contexto, que compreende a opinião e os argumentos dos alunos sobre os impactos sociais da inflação, denominamos de crítica sociopolítica. No quadro 3 apresentamos as falas dos alunos referentes a essa crítica. 
Quadro 3 - Discurso do Sujeito Coletivo impactos sociais da inflação.

Nós acreditamos que as famílias de baixa renda são as mais afetadas, seus maiores gastos são com a alimentação, o grande vilão foi esse setor. Para os indivíduos que dependem exclusivamente de um veículo para trabalhar, o aumento da gasolina foi um grande vilão. Um dos impactos está relacionado ao poder de compra, se uma família consome muito alguma coisa e a inflação aumenta, ela vai acabar parando de consumir. Os impactos da inflação na vida do brasileiro são seguintes: Quando se tem o reajuste salarial as pessoas podem ter uma falsa sensação de ganho, porém esse ajuste é feito pela inflação ou seja o dinheiro que a pessoa aparentemente perdeu em dado mês é retornado para ela, mas ela não tem lucro algum. Isso tem a ver com o ganho real. Também se torna necessário mais dinheiro para comprar dado produto, ou seja, o gasto é bem maior e com isso o poder de compra das pessoas acaba sendo um tanto reduzido. Quanto mais caro os produtos, menor será a procura, e isso prejudica a economia do país. Também, o poder de compra diminui e a moeda vai perdendo seu valor. As principais consequências da inflação são: a desvalorização da moeda, a diminuição do poder de compra da população, o aumento de preço dos produtos importados, diminuição do investimento internacional e o aumento da taxa de juros, que por sua vez aumenta a taxa de desemprego. Diferente para cada família, pois elas consomem coisas diferentes. Algumas são afetadas pela inflação e outras não. Por mais que o valor de inflação seja fixo ele representa situações diferentes para cada pessoa pois cada um possui uma renda e consomem produtos diferentes. Por exemplo, se a carne teve um aumento de preço uma pessoa vegetariana não seria afetada por isso. Por exemplo, se a família consome muito um produto cuja inflação é maior, essa família sentirá mais, o índice de inflação será maior. Os produtos básicos foram os que mais sofreram o impacto da inflação. As famílias que consomem apenas os produtos essenciais com a pequena renda são os mais afetados com as mudanças de preço.

Fonte: Material de pesquisa.

Com base no DSC apresentado no quadro 3, percebemos que os alunos foram capazes de pontuar algumas implicações que a inflação pode trazer a sociedade. Eles explicaram que esse fenômeno pode ser caracterizado pela: “ desvalorização da moeda, diminuição do poder de compra da população, aumento de preço dos produtos importados, diminuição do investimento internacional e aumento da taxa de juros, que por sua vez aumenta a taxa de desemprego". Nesse trecho vê-se que os alunos reconheceram a importância do equilíbrio dos preços para o bom desenvolvimento econômico de uma nação, denotando a compreensão, ainda que de maneira superficial, da lógica econômico-financeira, conforme defendido por Hofamann e Moro (2012) para a Educação Financeira.

A fala "Quando se tem o reajuste salarial as pessoas podem ter uma falsa sensação de ganho, porém esse ajuste é feito pela inflação, ou seja, o dinheiro que a pessoa aparentemente perdeu em dado mês é retornado para ela, mas ela não tem lucro algum. Isso tem a ver com o ganho real" revela a preocupação em relação à necessidade de um entendimento, por parte das pessoas, do que é ganho real e do que é ganho nominal. Ganho real é nome que se dá à rentabilidade obtida em determinado investimento, ou salário, conforme apontado pelo aluno, quando se desconta o impacto da inflação naquele período da 
chamada rentabilidade nominal. O que nos chama a atenção é o cuidado, revelado na fala do aluno, para que as pessoas tenham consciência do que de fato está sendo oferecido a elas.

Ainda sobre a crítica sociopolítica, destacamos as considerações a respeito de que o índice de inflação pode não ser igual para todas as famílias. Essa crítica os alunos construíram com base em dois argumentos diferentes, os quais relacionam-se ao consumo e à renda das famílias.

No que é relativo ao consumo, a crítica pode ser identificada nas falas "Para os individuos que dependem exclusivamente de um veículo para trabalhar, o aumento da gasolina foi um grande vilão" e "Por mais que o valor de inflação seja fixo ele representa situações diferentes para cada pessoa, pois cada um possui uma renda e consomem produtos diferentes". Vê-se que os alunos ponderam sobre um índice geral e as particularidades de consumo individuais. Eles reconheceram que, embora os índices de inflação tenham o objetivo de medir a tendência de variação de preços na economia, nenhum detecta exatamente o consumo da sua família, daí a necessidade de que as pessoas estejam conscientes de questões relacionadas ao consumo, trabalho e dinheiro, possibilitando tomadas de decisões mais assertivas.

No tocante às diferentes classes sociais, os alunos fizeram suas considerações apontando que as pessoas com rendas mais baixas são as mais impactadas pela inflação, o que foi identificado nas falas: “As famílias de baixa renda são as mais afetadas, seus maiores gastos são com a alimentação, o grande vilão foi esse setor" e "Os produtos básicos foram os que mais sofreram o impacto da inflação. As famílias que consomem apenas os produtos essenciais com a pequena renda são os mais afetados com as mudanças de preço". Por meio desses trechos, compreendemos que o entendimento de que as classes de baixa renda são as mais afetadas pela inflação foram validadas considerando que, no período analisado, os produtos que compões o grupo dos alimentos foram os que mais apresentaram alta nos preços.

Observa-se que a atividade realizada proporcionou que os alunos olhassem de maneira mais ampla para os dados, desafiando-os a pensar o que os dados indicam sobre a realidade. Para Campos (2016), é fazer esse movimento que possibilita o desenvolvimento da competência crítica, pois os estudantes são convidados a desvelar aspectos, muitas vezes ocultos na sociedade, por meio da Estatística. Complementarmente, cabe pontuar que a experiência pedagógica viabilizou tais discussões por lidar com dados reais, o que vai ao 
encontro do que é defendido por Campos (op. cit.). Para o autor, trabalhar com dados dessa natureza é a chave para desenvolver a criatividade e fomentar reflexões sobre sua própria realidade.

Quanto às vertentes da Educação Financeira, percebe-se nesse trabalho um destaque à vertente crítica, uma vez que não se buscou instrumentalizar os estudantes com ferramentas da Matemática Financeira, mas sobretudo os alunos foram convidados a refletir sobre a maneira de entender e interpretar a variação dos preços em um determinado período, bem como as implicações do índice de inflação na vida das pessoas. Conforme apresentado em Campos e Perin (2020), a Educação Financeira deve fomentar o espírito crítico, a responsabilidade ética e a conscientização política.

Neste trabalho, mostramos a Educação Financeira como um tema transversal na aula de Matemática na Educação Básica. O fio condutor foi composto por dois conceitos importantes da Estatística, a média e mediana, os quais foram abordados levando-se em consideração os pressupostos da Educação Estatística Crítica.

\section{CONSIDERAÇÕES FINAIS}

Neste texto buscamos mostrar a integração da Educação Estatística com a Educação Financeira mediante a realização de uma atividade de Modelagem Matemática envolvendo o tema inflação. Tomamos como base os pressupostos da Educação Estatística no que tange às competências denominadas literacia estatística e raciocínio estatístico, além da competência crítica conforme definida por Campos (2016), pois entendemos que as atividades pedagógicas, além de viabilizar a aprendizagem de conteúdos, devem favorecer que eles sejam utilizados para fazer uma leitura crítica de mundo. Assim, planejamos a atividade de tal forma que ela abrisse espaço para a análise e reflexão de situações que nos são cotidianas e que abrem caminho para o trabalho com as competências mencionadas.

Nossas análises revelaram que os alunos apreenderam conceitos importantes de Estatística, como média e mediana. Refletiram sobre suas especificidades, o que os levou a discernir em quais contextos cada uma delas deve ser empregada para representar um conjunto de dados. Como base nesses apontamentos, asseguramos o desenvolvimento de aspectos ligados à literacia e ao raciocínio estatístico.

Aprofundamos nossas discussões mostrando que o desenvolvimento dessas 
competências conduziu também ao desenvolvimento da competência crítica. Tal afirmação está alicerçada em nossas análises, as quais mostram que a realização da atividade não se restringiu à determinação de medidas estatísticas, mas fomentou uma reflexão sobre a ideia que cada uma delas traz subjacente quando usada para exprimir características de um fenômeno estudado. Chamamos reflexões como essas de crítica epistemológica, pois dizem respeito ao procedimento, à metodologia e aos resultados alcançados. Adicionalmente, os alunos buscaram compreender as decorrências da inflação na vida financeira das famílias, revelando o que chamamos de crítica sociopolítica.

Mediante uma atividade de modelagem matemática cujo objetivo era determinar e reconhecer a melhor medida estatística para representar a variação dos preços em um período, mostramos a possibilidade de integração da Estatística com a Educação Financeira em aulas de Matemática para o ensino médio. A Educação Financeira permeou todo o trabalho, no qual os alunos puderam estudar e aprender um novo conceito, a taxa de inflação.

\section{REFERÊNCIAS}

BARBOSA, Jonei Cerqueira. Modelagem na Educação Matemática: contribuições para o debate teórico. In: REUNIÃO ANUAL DA ANPED, 24., 2001, Caxambu, Anais [...].Rio de Janeiro, Anped, 2001. 1 CD-ROM.

BIEHLER, Rolf; FRISCHEMEIER, Daniel; READING, Chris; SHAUGHNSSY, Michael. Reasoning about data. In: BEN-ZVI, Dani; MAKAR, Katie; GARFIELD, Joan (orgs). International Handbook of Research in Statistics Education. Cham, Switzerland: Springer, 2018, p. 139-192.

BRASIL. Base Nacional Comum Curricular. Brasília: MEC/Secretaria de Educação Básica, 2018.

BURAK, Dionísio. A Modelagem Matemática na perspectiva da Educação Matemática: olhares múltiplos e complexos. Educação Matemática sem fronteiras, Chapecó, v. 1, n. 1, p. 96-111, 2019.

CAMPOS, Celso Ribeiro. A Educação Estatística: uma investigação acerca dos aspectos relevantes à didática da Estatística em cursos de graduação. 2007. Tese (Doutorado em Educação Matemática) - Instituto de Geociências e Ciências Exatas, Universidade Estadual Paulista, Rio Claro, 2007.

CAMPOS, Celso Ribeiro. Towards critical statistics education: theory and practice. Saarbrücken: Lambert Academic Publishing, 2016. 
Perin, A. P.; Campos, C. R.

CAMPOS, Celso Ribeiro; PERIN, Andréa Pavan. Educación financiera en la escuela primaria. In: X CONGRESO INTERNACIONAL SOBRE ENSEÑANZA DE LAS MATEMÁTICAS, 2020, Lima: Pontificia Universidad Católica del Perú, 2020, p. 240-248.

CAMPOS, Celso Ribeiro; WODEWOTZKI, Maria Lúcia Lorenzetti; JACOBINI, Otávio Roberto. Educação Estatística: teoria e prática em ambientes de modelagem matemática. Belo Horizonte: Autêntica, 2011.

GAL, Iddo. Adult statistical literacy: meanings, components, responsibilities. International Statistical Review, n. 70, v. 1, p. 1-25, 2002.

HOFMANN, Ruth Margareth; MORO, Maria Lucia Faria. Educação matemática e educação financeira: perspectivas para a ENEF. Zetetiké, n. 20 v. 38, p. 37-54, 2012

LEFREVE, Fernando; LEVREFE, Ana Maria Cavalcanti. Discurso do sujeito coletivo: representações sociais e intervenções comunicativas. Texto Contexto Enferm, n. 23, v. 2, p. 502-507, 2014.

ORGANISATION FOR ECONOMIC CO-OPERATION AND DEVELOPMENT. Improving Financial Literacy: analysis of issues and policies. Paris: Secretary-General of the OECD, 2005.

PERIN, Andréa Pavan. Educação Estatística Crítica: um estudo das práticas discentes em um curso de tecnologia. Tese (Doutorado em Educação Matemática) - Instituto de Geociências e Ciências Exatas, Rio Claro: Universidade Estadual Paulista, 2019.

PERIN, Andréa Pavan; CAMPOS, Celso Ribeiro. Interfaces entre Modelagem Matemática, Raciocínio e Pensamento Estatístico. Educação Matemática Debate, v. 4, n. 10, p-1-22, 2020 .

PERIN, Andréa Pavan; WODEWOTZKI, Maria Lúcia Lorenzetti. A modelagem matemática: um ambiente para o desenvolvimento do raciocínio estatístico. Caminhos da Educação Matemática em Revista, n. 9, v. 2, p. 158-170, 2019.

SENA, Franco Devys Lima. Educação Financeira e Estatística: Um estudo de estruturas de Letramento e Pensamento. 2017. Dissertação (Mestrado em Educação Matemática). São Paulo: PUC-SP, 2017.

Submetido em 10 de outubro de 2020. Aprovado em 22 de janeiro de 2021. 